\title{
Neonatal Formulations: The Need for a Tailored, Knowledge Driven Approach
}

\author{
Karel Allegaert ${ }^{1}$, Katrien Cosaert ${ }^{2}$ and John N van den Anker ${ }^{3,4,5,6}$
}

${ }^{1}$ Neonatal Intensive Care Unit and ${ }^{2}$ Hospital Pharmacy, University Hospitals Leuven, Leuven, Belgium; ${ }^{3}$ Division
of Pediatric Clinical Pharmacology, Children's National Medical Center, Washington, DC, USA and
${ }^{4}$ Departments of Pediatrics, Integrative Systems Biology, Pharmacology and Physiology, George Washington
University School of Medicine and Health Sciences, Washington, DC, USA, Intensive Care, Erasmus MC-Sophia
Children's Hospital, Rotterdam, the Netherlands and ${ }^{5}$ Department of Paediatric Pharmacology, University Chil-
dren's Hospital Basel, Switzerland

Abstract: To attain effective and safe pharmacotherapy in neonates, caregivers have to consider both the clinical characteristics of the newborn and the pharmacokinetic estimates of a given compound during prescription and administration. Overall, clearance in neonates is low when compared to other pediatric subpopulations. Despite this overall low clearance, there is already extensive between individual variability in clearance in early life. As a consequence, neonates are in urgent need of tailored drug product development that considers the need for both low and flexible dosing to maintain dose accuracy.

During the development of such formulations tailored for neonates, there is also a need for guidance on excipient exposure. The available knowledge on the safety or toxicity of excipients is limited and difficult to retrieve, but there are initiatives (e.g. Safety and Toxicity of Excipients for Pediatrics [STEP] database initiative) to improve the present situation. In addition, population focussed studies on aspects of clinical pharmacology of excipients in neonates should be conducted. The propylene glycol research project and the European Study for Neonatal Excipient Exposure (ESNEE) initiative illustrate its feasibility. Finally, until tailored formulations make it to the market, compounding practices for drug formulations in neonates should be evaluated to guarantee correct dosing, product stability, safety and to support pharmacists in their daily practice.

Keywords: ?????????????

\section{INTRODUCTION}

Effective and safe drug administration in neonates should be based on the integration of knowledge related to the evolving physiological characteristics of the newborn to be treated with a given compound, and the pharmacokinetic and pharmacodynamics characteristics of this specific compound [1-4]. Children display maturation in the disposition of drugs, and this maturation is most pronounced in the first months of postnatal life. There are agedependent changes in body composition (e.g. water content) while almost all phase I (e.g. cytochrome P450 iso-enzymes) and phase II (e.g. glucuronidation, sulphation) metabolic processes mature with an iso-enzyme specific pattern. In addition, renal elimination clearance also displays a maturational increase and almost exclusively depends on glomerular filtration [1-4].

The limited size $(0.5-5 \mathrm{~kg})$ does not exclude an extensive variability in clearance within this specific group of patients since there is already one log value in weight differences. Even more than the low median estimates of clearance, covariates of variability within this specific population are of clinical relevance. Besides weight, other covariates (e.g. co-medication, perinatal asphyxia, intrauterine growth restriction, postnatal age, postmenstrual age) further contribute to the variability in clearance within the neonatal population $[5,6]$.

When we aim to translate the combination of the overall low clearance with extensive variability within the neonatal age range, this results in the need for both low, adjustable and flexible dosing in early life to maintain dosing accuracy. As a consequence, formulations for neonates need to consider these prerequisites [7]. Because of the specific characteristics of neonates, commonly

\footnotetext{
*Address correspondence to this authora at the Neonatal Intensive Care Unit, University Hospital, Herestraat 49, 3000 Leuven, BELGIUM; Tel: 0032-16-343850; Fax: 00-32-16-343209; E-mail: karel.allegaert@uzleuven.be
}

administered formulations are either liquids (e.g. drops, syrup) or vials for intravenous administration. The available data on the relevance and the add-on value of tailored formulations in neonates will be discussed. This also includes the aim to validate the practice of extemporaneous formulation or compounding for neonates. Tailored formulations hereby aim to result in more accurate, predictable and safe exposure to drugs for neonates $[1,7]$.

A specific issue that warrants focussed attention in neonatal formulation are the excipients used. As recently reviewed in this journal, pattern recognition of covariates should improve the feasibility to perform clinical studies and to guide product development for neonates [4]. The same above mentioned maturational changes will also have impact on the pharmacokinetics and -dynamics of excipients (i.c. 'excipient'-kinetics and -dynamics) commonly used during product development [8-10]. Consequently, there is an urgent need to collect and summarize the already available knowledge on the clinical pharmacology of excipients in neonates: to make already available data accessible. The approach used in the development of the Safety and Toxicity of Excipients for Paediatrics (STEP) database will be discussed as an illustration of this approach [11]. Such databases should provide us with data on knowledge gaps in need of focussed research initiatives: to generate data on the knowledge gaps. We will illustrate the feasibility of such research initiatives based on the Leuven propylene glycol research project and on the European Study for Neonatal Excipient Exposure (ESNEE) initiative [12-16].

The relevance of tailored formulations in neonates we be discussed first. This also includes the validation of compounding practices. This will be followed by topics related to the population specific clinical pharmacology of excipients in neonates. We hereby aim to describe a roadmap to further improve the pharmaceutical practice for (pre)term neonates. 


\section{NEONATAL DRUG FORMULATIONS}

\section{The Relevance of Tailored Formulations}

Neonates should receive formulations of which the pharmaceutical design is tailored for use in this specific population $[5,9,17$, $18]$. Volume overload should be avoided, while too low volumes or too concentrated formulations may result in either dose inaccuracy due to either inaccurate volumes or inaccurate serial dilutions in order to achieve the required dose $[17,18]$. There are observations on the impact of serial dilutions of inotropics to illustrate the extent of dosing inaccuracy [19]. In contrast, a recent illustration of such an tailored formulation approach for neonates is the development of a caffeine containing vial (Peyona ${ }^{\circledR}$ ) for treatment of apnoea of prematurity $(20 \mathrm{mg} / \mathrm{ml}$ of caffeine citrate, equal to $10 \mathrm{mg} / \mathrm{ml}$ of caffeine base).

Nunn et al. recently quantified the practice of medicines manipulation to provide accurate doses for children, including neonates in one regional children's hospital [20]. Based on 5375 drug administration events recorded in neonatal and pediatric patients, about $10 \%$ were judged to require manipulation or needed a small dosing volume $(<0.2 \mathrm{ml})$. Measure doses below $0.1 \mathrm{ml}$ accounted for $25 \%$ of the manipulations, and this was most common in the neonatal intensive care unit (60\%) [20].

Oral administration can be achieved by several types of dosage forms. However, because of the need for dosing flexibility and the inability to swallow solid unit dosage forms, oral liquid formulations (e.g. syrup, liquid drops) are preferred in neonates and young infants $[3,21,22]$. For the enteral route, specific issues that need to be considered in neonates are the impact of tube feeding or simultaneous administration with milk on the bioavailability of the pharmaceutical product. For oral drugs commonly administered by a feeding tube (e.g. in preterm neonates), issues related to particle size, viscosity, dosing volume and compatibility with the tube material should be considered [3,21,22].

Most vials for intravenous administration contain relatively high concentrations of the active compound, inadequate for small neonates or infants. Tailored vials for intravenous administration, resulting in appropriate, flexible and correct dosage of drugs in neonates are needed. Besides the fact that 10 fold errors are more common when 'highly' concentrated formulations are used, this also relates to dilution related errors resulting in dosing inaccuracy $[7,18,23,24]$.

We have illustrated this for amikacin (pediatric vial $50 \mathrm{mg} / \mathrm{ml}$ compared to the 'adult vial' $250 \mathrm{mg} / \mathrm{ml}$ ), hereby applying a population PK approach (NONMEM) to estimate clearance (CL) and volume of distribution (V) changes as markers for dose accuracy and variability from time-concentration profiles [25]. Differences in parameter estimates and their variability before and after introduction of the $50 \mathrm{mg} / \mathrm{ml}$ pediatric vial hereby reflect differences in dose accuracy. The final model demonstrated an apparent $8 \%$ reduction in the estimate of $\mathrm{V}$ and a $29 \%$ reduction of its variability after introduction of the pediatric vial. Clearance was the same in neonates given adult or pediatric vials, but clearance variability was reduced by $53 \%$. Based on these observations, we concluded that the introduction of a pediatric vial was associated with a reduction in $\mathrm{V}$ and $\mathrm{CL}$ variability, reflecting improved dosing precision $[23,25]$.

\section{The Practice of Compounding: Towards a Knowledge Driven Approach}

At present, it is unlikely that commercially manufactured, ready-to-administer neonatal preparations are available for all compounds prescribed. Marketed formulations do not always meet the specific requirement of all patient groups, commonly applicable for neonates (formulation, dose). As a consequence, it is reasonable to assume that compounding practices will remain common practice in near future $[22,26,27]$.
The first intent of the manufacturer should be to provide an age appropriate formulation. An alternative could be that the manufacturer provides evidence on an appropriate compounding of a given formulation. A recent illustration of such an approach is the compounding of an oral solution of valganciclovir [28]. Unfortunately, non-authorised (i.e. information not included in the Summary of product characteristics $[\mathrm{SmPC}]$ ) compounding or manipulation is still very common, although the quality of compounding and excipient ingredients may vary considerably. This non-authorised approach may facilitate the use of a given drug in neonates but is unlicensed, and obviously carries risks of patient safety related to the quality of the formulation, the bioavailability of the compound and the excipients used for compounding [21,29]. A recent illustration of the need to validate such compounding practices is the evaluation of a paediatric oral formulation with a low proportion of hydrochlorothiazide, also suited for use in neonates. Santovena et $a l$. hereby illustrated that only one of 5 suspensions of hydrochlorothiazide $(2 \mathrm{mg} / \mathrm{ml})$, guaranteed the correct dose administering and stability after 3 weeks of storage in predefined conditions [30].

\section{EXCIPIENTS IN NEONATAL DRUG FORMULATIONS}

\section{Commonly Co-Administered, Rarely Considered}

In addition to the parent compounds, drug formulations also contain excipients, needed as co-solvents, surfactants (general term for compounds that improve absorption, unrelated to the lung 'surfactant' administered for hyaline membrane disease), preservatives, colorants or sweeteners [31-33]. Examples of excipients are lactose, aspartame, ethanol, propylene glycol, benzyl alcohol, sorbitol, xylitol, mannitol and poly-ethylene glycol. Such a definition suggest that excipients are only 'innocent bystanders' of the active compound(s) in a specific formulation.

More recently, a more dynamic definition has been applied by the United States' National Formulary [34]. This institution hereby refers to an excipient as 'everything in the formulation in addition to the active compound(s)'. It refers to any substance that is used as vehicle or additive for administering drugs in the suitable consistency or formulation. These excipients are added e.g. to ensure stability over a given shelf life, to improve palatability or to facilitate solubility or to bulk up formulations that otherwise contain highly potent active ingredients and are referred to as preservatives, sweeteners, fillers and solvents, coating materials or colouring agents [34].

In addition, excipients can further modulate the effects of a therapeutic compound. Examples of such more 'interactive' applications are e.g. liposomal amphotericin to avoid renal tubular toxicity related to unbound amphotericin filtered by the renal glomerulus and subsequent resorption at the renal tubular cell [35]. Similarly, experimental data suggest that erythropoietin administration may serve as additional neuroprotective agent in neonates following peripartal asphyxia but that the positive effects in part depend on the permeability of the effect compartment (i.c. central nervous system) for erythropoietin [36]. In animal experimental setting, it has recently been described that transfer through the blood brain barrier of a nano-formulation (human recombinant EPO, PLGAEPO nanoparticles) results in a 10 fold higher bio-availability in the effect compartment [36]. As final illustration, the efficacy of inactivated influenza vaccines is known to be poor in early life, but the use of an oil-in-water emulsion adjuvant results in a effective protection, defined by a reduction in influenza attack rates [37].

Although nearly all medicines are formulated with excipients that have been used for many years and are generally regarded $\boldsymbol{a}$ s safe, usually referred to as 'GRAS' status, there are still disease specific issues (e.g. aspartame in patients with phenylketonuria, lactose in patients with lactase deficiency), and also issues related to specific populations like (pre)term neonates with their specific pharmacokinetics and-dynamics that needs further consideration 
$[32,34]$. Historical observations, but also more recent case series repeatedly confronted clinicians with unanticipated, but sometimes predictable side-effects of neonatal drug formulations merely because of the excipients co-administrated. Benzyl alcohol [38-42] and propylene glycol $[12,13,42,43]$ will be used as illustrations of the relevance to consider pharmacokinetics, while ethanol can be used as an example to consider pharmacodynamics of excipients in neonates [44]. Table 1 provides some additional information on the link between clinical syndromes and excipient exposure in neonates.

Table 1. Illustrations of specific clinical syndromes in neonates and associated excipient exposure.

\begin{tabular}{|l|l|}
\hline Specific clinical syndrome & \multicolumn{1}{|c|}{ excipient exposure } \\
\hline \hline Raised hyperbilirubinaemia & $\begin{array}{l}\text { parabens (methyl- and propyl parahy- } \\
\text { droxybenzoate) sodium benzoate }\end{array}$ \\
\hline Seizures & $\begin{array}{l}\text { propylene glycol, accumulation benzyl } \\
\text { alcohol, accumulation }\end{array}$ \\
\hline $\begin{array}{l}\text { Central nervous system } \\
\text { depression }\end{array}$ & $\begin{array}{l}\text { ethanol, accumulation propylene glycol, } \\
\text { accumulation }\end{array}$ \\
\hline $\begin{array}{l}\text { Liver dysfunction, cho- } \\
\text { lestasis }\end{array}$ & $\begin{array}{l}\text { propylene glycol, accumulation polysor- } \\
\text { bate } 80\end{array}$ \\
\hline Metabolic acidosis & $\begin{array}{l}\text { propylene glycol, accumulation polysor- } \\
\text { bate } 80 \text { benzyl alcohol }\end{array}$ \\
\hline
\end{tabular}

Fatal benzyl alcohol-related poisoning has been described in a case series of 10 low birth weight infants. Benzyl alcohol was coadministered in these neonates since included in an intravenous formulation as a bacteriostatic agent [38-41]. After administration of at least $130 \mathrm{mg} / \mathrm{kg}$ of benzyl alcohol, these neonates developed metabolic acidosis and had an elevated Anion Gap from the second day of exposure onwards. These neonates subsequent developed progressive bradycardia, gasping and seizures [38-41]. Based on these observations, evidence was collected that this clinical syndrome in neonates is related to maturational deficiency of benzyl alcohol degradation (benzyl alcohol to benzoic acid to hippuric acid) capacity, resulting in accumulation and subsequent toxic effects [38-41].

Propylene glycol toxicity in preterm neonates has also been documented since preterm neonates developed biochemical abnormalities, including hyperosmolarity, lactic acidosis, elevated creatinine and bilirubin following exposure of up to $3000 \mathrm{mg} /$ day of propylene glycol for at least 5 days. These biochemical abnormalities were followed by clinical symptoms, including seizures and bradycardic episodes $[45,46]$. Only recently, it was described that there is a much lower clearance capacity in neonates, in part depending on birth weight and on postnatal age [43].

Although these case series go back to the 1980 s, the propylene glycol example also illustrates that this issue still remains of contemporary relevance. In March 2011, The US Food and Drug Administration notified healthcare professionals of serious health problems that had been reported in premature babies receiving Kaletra ${ }^{\circledR}$ (lopinavir/ritonavir) oral solution [47]. This is an antiviral medication used in combination with other antiretroviral drugs for the treatment of HIV-1 infection. However, this Kaletra oral solution contains both relevant amounts of ethanol $(42.4 \% \mathrm{v} / \mathrm{v})$ and propylene glycol $(15.3 \% \mathrm{w} / \mathrm{v})$. Based on the reported side effects, the FDA claimed that premature babies may be at increased risk for health problems because they have a decreased ability to eliminate propylene glycol. This limited elimination capacity potentially results in adverse events such as serious cardiac, renal, metabolic and respiratory problems. Because the consequences of using Kaletra oral solution in neonates immediately after birth can be severe or possibly fatal, the label has undergone revision to include a new warning. The use of Kaletra oral solution should be avoided in premature babies until 14 days after their due date, or in full-term babies younger than 14 days of postnatal age unless a healthcare professional believes that the benefit of using Kaletra oral solution to treat HIV infection immediately after birth outweighs the potential risks. In such cases, FDA strongly recommends monitoring for increases in serum osmolality, serum creatinine, and other signs of toxicity [47].

In addition to maturational pharmacokinetics, maturational pharmacodynamics should also be considered. Ethanol is known to be a neurotoxic compound, with age-specific impact on the fetal or neonatal brain (i.c. apoptosis and impaired synaptogenesis) with e.g. fetal alcohol syndrome [44]. Despite this, ethanol is still commonly used as an excipient for oral liquid formulations in (pre)term neonates.

\section{Lessons Learned from Recent Observations on Excipients}

To raise awareness, we would like to stress that the above described excipients are compounds to which neonates are quite regularly exposed to in our neonatal intensive care units. Recent observations on the extent of the exposure have been reported from the United Kingdom [48], the United States [42], the Netherlands [49], Belgium $[12,13,43]$ and most recently, from Estonia $[14,15]$. The key observations reported on the different epidemiological survey are also summarized in Table $\mathbf{2}$

\section{Table 2. Lessons learned on contemporary excipient exposure} in neonates.

exposure is common: different cohorts in different countries all provide evidence for consistent, established exposure to excipients, including excipients linked to relevant clinical syndromes in neonates.

the range in exposure is extensive: despite the established exposure, there is relevant variability in the amount of excipients exposed to. Bronchopulmonary dysplasia and critical illness were two relevant covariates that were associated with higher excipient exposure.

exposure is difficult to quantify: excipients are commonly but not routinely mentioned on formulations. Even if mentioned qualitatively, amounts are only rarely mentioned on the SmPC. This has been observed in different settings.

exposure can be avoided: Interestingly, there are different formulations for different active compounds. There is a gentamicin formulation containing both parabens and sodium metabisulphite, while another formulation is free of these excipients. Similar, phenobarbital formulations contain different amounts of propylene glycol (5 fold difference when expressed in $\mathrm{mg}$ propylene glycol/mg phenobarbital) and there is even an formulation free of propylene glycol. This means that to a certain extent, excipient exposure can even be avoided.

Whittaker et al. [48] quantified the extent of exposure to potential toxic excipients following administration of oral formulations in preterm neonates. These research groups hereby documented that $53 \%$ of the eligible target group were exposed to potential toxic excipients during their in-patient stay. These infants were exposed to over 20 excipients including ethanol and propylene glycol, chemicals associated with neurotoxicity. Infants with chronic lung disease were exposed to higher concentrations of these excipients. Infants were also exposed to high concentrations of sorbitol, with some infants being exposed to concentrations in excess of recommended guidelines for maximum exposure in adults. Similar, the ethanol exposure was also commonly above 1 unit/week of adult equivalent intake. Finally, propylene glycol exposure, co- 
administered with a dexamethasone liquid formulation commonly resulted in a weekly exposure above the $150 \mathrm{mg} / \mathrm{kg} /$ week limit for adults [48]. Likewise, Shehab et al. quantified the exposure to benzyl alcohol and propylene glycol in critically ill neonates or infants [42]. Based on 170 episodes of benzyl alcohol $(n=88)$ and/or propylene glycol $(\mathrm{n}=82)$ exposure, a wide range in cumulative excipient dose was documented [4.5 (0.6-319) $\mathrm{mg} / \mathrm{kg} /$ day for benzyl alcohol and $204.9(17-9473) \mathrm{mg} / \mathrm{kg} /$ day for propylene glycol respectively][42].

Riet-Nales et al. reviewed the availability and ageappropriateness of medicines for children in the Netherlands [49]. In an at random sample of 400 oral liquid preparations, authorization for use in newborns was limited (37\%), and $52 \%$ contained potential harmful excipients. For parenteral preparations, $7 \%$ contained potential harmful excipients. Interestingly, the same active compound but without such 'potential harmful' excipient was available in $22 \%$ of the formulations [49].

In Belgium, we recently reported on a focussed study on aspects of the clinical pharmacology of propylene glycol exposure following intravenous co-administration in neonates $[12,13,43]$. We hereby documented that a median exposure to $34 \mathrm{mg} / \mathrm{kg} /$ day of propylene glycol was tolerated well [13]. Interestingly, during the design of the study, we also had difficulties to retrieve the exact composition of the propylene glycol containing phenobarbital vial commonly used in our unit [12].

Recently (2012), a nationwide survey on the extent of excipient exposure to neonates has been reported from Estonia [14,15]. Based on 1961 prescriptions on 107 different formulations during a 6 month time interval, exposure to 123 excipients in $348 / 490$ neonates was documented. Of these excipients, 47/123 (38\%) were classified as 'toxic or potential toxic' for neonates. Almost all admitted neonates $(97 \%)$ were exposed to at least one for these 'toxic or potential toxic' excipients [14,15]. Despite the fact that 19 formulations were licensed for use in neonates, about half of them contained at least one potential harmful excipient.

Parabens and sodium metabisulphite were the most commonly administered 'toxic or potential toxic' excipients administered in this Estonian cohort but exposure to sodium benzoate, benzyl alcohol, propylene glycol, polysorbate 80 and ethanol was also observed $[14,15]$. Interestingly, the exposure to parabens and sodium metabisulphite seems to relate to a specific gentamicin formulation available in Estonia. The authors hereby mention that the information currently mentioned on the SmPC was not always complete, that the amount of excipients in a specific formulation was only mentioned in 2/19 SPC documents approved for use in (pre)term neonates. This confirms the Belgian observation on the difficulties to retrieve the exact amounts of propylene glycol in intravenous phenobarbital formulations administered to newborns [12]. Moreover, it turned out that there are also parabens/sodium metabisulphite free gentamicin formulations and even propylene glycol free phenobarbital formulations available in some specific countries or regions $[14,15,50]$.

\section{Towards a Tailored, Knowledge Driven Approach of Excipients}

The recent epidemiological findings confirm the established exposure to excipients, the difficulty to retrieve the exact amounts of exposure, and the unanticipated observations that both excipient containing and excipient free formulations for the same therapeutic compound are available. Recently initiated research activities to ameliorate the access to information on excipients in neonates (STEP database, i.e. Safety and Toxicity of Excipients for Paediatrics database) [11] or to generate new information (ESNEE research initiative, European Study for Neonatal Excipient Exposure) on the epidemiology and the tolerance of excipients are very useful approaches [16].
Excipient safety data are publicly available in peer-reviewed scientific journals, government reports and databases, but there is limited information on data to guide neonatal drug development. Moreover, the available information is distributed over many sources. The European Paediatric Formulation Initiative (EuPFI) took - in collaboration with the Food and Drug Administration, European Medicines Agency and pharmaceutical industry - the initiative to collect and structure retrievable information on excipients in the 'STEP' database. The main aims of this STEP initiative are (1) to conduct a systematic review on the pharmacology, toxicology and safety data of excipients considered to be used in paediatric formulations, (2) to help determine the relationship between exposure and toxicity in the paediatric age group or in specific paediatric subpopulations like neonates, and (3) to identify knowledge gaps and needed studies [11]. Such a database provides stakeholders a basis for screening and selecting excipients for use in paediatric product development.

The European Study for Neonatal Excipient Exposure (ESNEE research initiative) has been funded by the ERA-NET PRIOMEDCHILD, a multinational European research initiative with specific focus on developmental clinical pharmacology [16]. This research initiative aims to build a platform for systematic assessment of excipients in neonates. The first step is about 'setting the scene': which excipients are in use and how much of each excipient is included in medicines given to neonates. The above described data on excipient exposure in Estonian neonates related to this ESNEE initiative [16]. A second step of this ESNEE program is to determine what is known about the effects of excipients in neonates and juvenile animals. To do so, the research initiative aims to develop a series of systematic reviews about excipient toxicity in neonates.

The third step is to 'generate information on missing links': to quantify concentrations of key excipients in neonates using dry blood spots and plasma samples. The final step of the ESNEE program is to integrate this work into a systematic assessment of safety for each excipient: 'back to the clinical relevance'. A generic framework for the assessment of excipient safety in neonates will be developed [16]. Propylene glycol may hereby serve as a case study with reference to other excipients to at least illustrate its feasibility. We recently published our experiences on the feasibility and the methodology applied to evaluate pharmacokinetics and dynamics of propylene glycol $[12,13,43]$. This approach included population pharmacokinetics, systematic collection of clinical observations and comparison of excipient exposed compared to nonexposed neonates $[12,13]$.

\section{GENERAL DISCUSSION}

Children display maturation in drug disposition, but this is most prominent in the first months of postnatal life. Although the principles of drug disposition also apply in neonates, their specific characteristics warrant focussed assessment. As a consequence, neonates are in need of tailored drug development and clinical research should hereby focus on both new as well as already existing compounds [27,51,52]. Good prescribing involves assurance that the drug administered is of sufficient pharmaceutical quality, that an appropriate formulation is used (excipient, dose accuracy), and that there is sufficient knowledge on the pharmacokinetics, -dynamics and safety of the compound administered [27,51,52].

We hereby aimed to stress that tailored, personalized clinical pharmacology for neonates also needs considerations related to neonatal formulations and additives. Similar to the increasing knowledge on clinical pharmacology of the active compounds administered to neonates, we should aim to increase the knowledge and the validity of this knowledge on excipient exposure in neonates [22,31]. We need to learn more on the appropriateness of established excipient use in neonatal drug formulations $[9,10$, $27,48]$. We hereby have to aware that authorised medicinal products with given excipients do not necessary reflect the gold standard, nor 
does this validate the unrestricted use of the same excipient in another formulation: established practice is not always equal to best practice [5,52].

Further progress can be made in collaborative efforts between industry, caregivers, academia and regulatory agencies and should focus on product availability (tailored formulations), knowledge integration of currently available information and make such information accessible (e.g. STEP database), validation of the assumed safety of currently used excipients (ESNEE study project), and the validation of procedures and practices on compounding.

\section{CONFLICT OF INTEREST}

The authors confirm that this article content has no conflicts of interest.

\section{ACKNOWLEDGEMENTS}

Karel Allegaert is supported by the Fund for Scientific Research, Flanders (Fundamental Clinical Investigatorship $1800209 \mathrm{~N})$. The clinical research of J.N. van den Anker is supported by the NIH grants (5R01HD048689; 5K24DA027992; 5R01HD060543) and FP7 grants TINN (223614), TINN2 (260908), and NEUROSIS (223060).

\section{REFERENCES}

[1] Kearns GL, Abdel-Rahman SM, Alander SW, Blowey DL, Leeder JS, Kaufman RE. Developmental pharmacology: drug disposition, action, and therapy in infants and children. N Engl J Med 2003; 349: 1157-1167.

[2] Allegaert K, Verbesselt R, van den Anker JN, et al. Developmental pharmacology: since neonates are not just small adults. Acta Clin Belg 2008; 63: 16-24.

[3] Fanos V, Yurdakök M. Personalized neonatal medicine. J Matern Fetal Neonatal Med 2010; 23(Suppl 3):4-6.

[4] Smits A, Kulo A, de Hoon JN, Allegaert K. Pharmacokinetics of drugs in neonates: pattern recognition beyond compound specific observations. Curr Pharm Des 2012; 18: 3119-3146.

[5] Turner MA. Neonatal drug development. Early Hum Dev 2011; 87: 763-768.

[6] Van den Anker JN. Managing drugs safely. Semin Fetal Neonatal Med 2005; 10: 73-81.

[7] Broussard L. Small size, big risk: preventing neonatal and pediatric medication errors. Nurs Womens Health 2010; 14: 405-408.

[8] Fabiano V, Mameli C, Zuccotti GV. Paediatric pharmacology: remember the excipients. Pharmacol Res 2011; 63: 362-365.

[9] McIntyre J, Choonara I. Drug toxicity in the neonate. Biol Neonate 2004; 86: 218-221.

[10] Ligi I, Boubred F, Grandvuillemin I, Simeoni U. Clinical research in newborn infants: difficulties and specificity. Eur J Clin Pharmacol 2011; 67(Suppl 1): S29-S32.

[11] Salunke S, Giacoia G, Tuleu C: The STEP (Safety and Toxicity of Excipients for Paediatrics) database. Part 1 - A need assessment study. Int J Pharm 2012;435:101-111.

[12] Kulo A, de Hoon J, Allegaert K. The propylene glycol research project to illustrate the feasibility and difficulties to study toxicokinetics in neonates. Int J Pharm 2012; 435: 112-114.

[13] Allegaert K, Vanhaesebrouck S, Kulo A, et al. Prospective assessment of short-term propylene glycol tolerance in neonates. Arch Dis Child 2010; 95: 1054-1058.

[14] Lass J, Käär R, Jõgi K, Varendi H, Metsvaht T, Lutsar I. Drug utilisation pattern and off-label use of medicines in Estonian neonatal units. Eur J Clin Pharmacol 2011; 67: 1263-1271.

[15] Lass J, Naelapaa K, Shah U, et al. Hospitalised neonates in Estonia commonly receive potentially harmful excipients. BMC Pediatr 2012; 12: 136 .

[16] Turner MA, Storme T: European study of neonatal excipient exposure (ESNEE). Eur J Hosp Pharm 2012;19:67.

[17] Walsch J. Excipients for the formulation of medicines for children. Eur Indust Pharm 2012; 13: 14-16.

[18] Caldwell NA, Rackham O. Children's doses should be measurable. Arch Dis Child 2010; 95: 313.
[19] Rosenbluth G, Wilson SD. Pediatric and neonatal patients are particularly vulnerable to epinephrine dosing errors. Ann Emerg Med 2010; 56: 704-705

[20] Nunn A, Craig JV, Shah UU, et al. Estimating the requirement for manipulation of medicines to provide accurate doses for children. Eur J Hosp Pharm doi 10.1136/ejhpharm-2012-000133.

[21] Dessi A, Salemi C, Fanos V, Cuzzolin L. Drug treatments in a neonatal setting: focus on the off-label use in the first month of life. Pharm World Sci 2010; 32: 120-124.

[22] Jacqz-Aigrain E. Drug policy in Europe research and funding in neonates: current challenges, future perspectives, new opportunities. Early Hum Dev 2011; 87 (suppl 1): S27-S30.

[23] Sherwin CM, McCaffrey F, Broadbent RS, Reith DM, Medlicott NJ. Discrepancies between predicted and observed rates of intravenous gentamicin delivery for neonates. J Pharm Pharmacol 2009; 61: 465-471.

[24] Uppal N, Yasseen B, Seto W, Parshuram CS. Drug formulations that require less than $0.1 \mathrm{~mL}$ of stock solution to prepare doses for infants and children. CMAJ 2011; 183: E246-E248.

[25] Allegaert K, Anderson BJ, Vrancken M, et al. Impact of a paediatric vial on the magnitude of systematic medication errors in preterm neonates: amikacin as an example. Paed Perinatal Drug Ther 2006; 7: 59-63.

[26] Dabliz R, Levine S. Medication safety in neonates. Am J Perinatol 2012; 29: 49-56.

[27] Turner MA, Lewis S, Hawcutt DB, Field D. Prioritising neonatal medicines research: UK Medicines for Children Research Network scoping survey. BMC Pediatr 2009 Aug 12; 9: 50.

[28] Acosta EP, Brundage RC, King JR: Ganciclovir population pharmacokinetics in neonates following intravenous administration of ganciclovir and oral administration of a liquid valganciclovir formulation. Clin Pharmacol Ther 2007;81:867-872.

[29] Richey RH, Craig JV, Shah UU, et al. The manipulation of drugs to obtain the required dose: systematic review. J Adv Nurs 2012; 68: 2103-2112

[30] Santovena A, Hernandeze-Paiz Z, Farina JB. Design of a pediatric oral formulation with a low proportion of hydrochlorothiazide. Int $\mathrm{J}$ Pharm 2012; 423: 360-364.

[31] Nahata MC. Safety of "inert" additives or excipients in paediatric medicines. Arch Dis Child Fetal Neonatal Ed 2009; 94: F392-F393.

[32] American Academy of Pediatrics, Committee on Drugs: Inactive ingredients in pharmaceutical products: update (subject review). Pediatrics 1997; 99: 268-278.

[33] Tuleu C, Breitkreutz J. Formulation related issues in paediatric clinical pharmacology. Eur J Pediatr (in press).

[34] Hamman J, Steenekamp J. Excipients with specialized functions for effective drug delivery. Expert Opin Drug Deliv 2012; 9: 219-230.

[35] Turkova A, Roilides E, Sharland M: Amphotericin B in neonates: deoxycholate or lipid formulation as first-line therapy - is there a 'right' choice? Curr Opin Infect Dis 2011;24:163-171.

[36] Chen H, Spagnoli F, Burris M, et al. Nanoerythropoietin is 10-times more effective than regular erythropoietin in neuroprotection in a neonatal rat model of hypoxia and ischemia. Stroke 2012; 43: 884887.

[37] Vesikari T, Knuf M, Wutzler P, et al. Oil-in-water emulsion adjuvant with influenza vaccine in young children. N Engl J Med 2011; 365: 1406-1416.

[38] Gershanik J, Boecler B, Ensley H, McCloskey S, George W. The gasping syndrome and benzyl alcohol poisoning. $\mathrm{N}$ Engl J Med 1982; 307: 1384-1388.

[39] LeBel M, Ferron L, Masson M, Pichette J, Carrier C. Benzyl alcohol metabolism and elimination in neonates. Dev Pharmacol Ther 1988; 11: 347-356.

[40] Jardine DS, Rogers K. Relationship of benzyl alcohol to kernicterus, intraventricular haemorrhage, and mortality in preterm infants. Pediatrics 1989; 83: 153-160.

[41] Brown WJ, Buist NR, Gipson HT, Huston RK, Kennaway NG. Fatal benzyl alcohol poisoning in a neonatal intensive care unit. Lancet 1982; 8283: 1250 .

[42] Shehab N, Lewis CL, Streetman DD, Donn SM. Exposure to the pharmaceutical excipients benzyl alcohol and propylene glycol among critically ill neonates. Pediatr Crit Care Med 2009; 10: 256259.

[43] De Cock RF, Knibbe CA, Kulo A, et al. Developmental pharmacokinetics of propylene glycol in preterm and term neonates. $\mathrm{Br} J$ Clin Pharmacol 2012, doi 10.111/j.1365-2125.2012.04312.x. 
[44] Zuccotti GV, Fabiano V. Safety issues with ethanol as an excipient in drugs intended for pediatric use. Expert Opin Drug Saf 2011; 10: 499-502.

[45] MacDonald MG, Fletcher AB, Johnson EL, Boeckx RL, Getson PR, Miller MK. The potential toxicity to neonates of multivitamin preparations used in parenteral nutrition. JPEN J Parenter Enteral Nutr 1987; 11: 169-171.

[46] MacDonald MH, Getson PR, Glasgow AM, Miller MK, Boeckx RL, Johnson EL. Propylene glycol: increased incidence of seizures in low birth weight infants. Pediatrics 1987; 79: 622-625.

[47] No authors listed: Lopinavir + ritonavir oral solution: dangerous form for newborns. Prescrire Int 2011;20:237.

[48] Whittaker A, Currie AE, Turner MA, Field DJ, Mulla H, Pandya HC. Toxic additives in medication for preterm infants. Arch Dis Child Fetal Neonatal Ed 2009; 94: F236-F240.
[49] Van Riet-Nales DA, de Jager KE, Schobben AF, Egberts TC, Rademaker CM. The availability and age-appropriateness of medicines authorized for children in The Netherlands. Br J Clin Pharmacol 2011; 72: 465-473.

[50] Kawada K, Itoh S, Itani Y, et al. A clinical trial assessing the efficacy and safety of a new injectable formula of sodium phenobarbital containing no additives for the treatment of neonatal seizures. Jpn J Clin Pharmacol Ther 2011; 42: 205-210.

[51] de Cock R, Piana C, Krekels EH, et al. The role of population PKPD modelling in paediatric clinical research. Eur J Clin Pharmacol 2011; 67(Suppl 1): S5-S16.

[52] Rieder M. If children ruled the pharmaceutical industry: the need for pediatric formulations. Drug News Perspect 2010; 23: 458-464. 